\title{
Survey of Mental Illness in Adolescence
}

\author{
A. S. HENDERSON,* M.B., CH.B.(ABERD.), M.R.C.P., M.R.A.C.P., D.P.M. \\ J. W. MCCULLOCH, $\dagger$ M.SC.ED., A.A.P.S.W. ; A. E. PHILIP,* M.A. (ABERD.), DIP.CLIN.PSYCHOL.
}

Brit. med. 7., 1967, 1, 83-84

There is a need for more precise information on mental illness among adolescents. To date, studies of the incidence or prevalence of psychiatric morbidity in a community (Kessel, 1960 ; Srole et al., 1962 ; Taylor and Chave, 1964 ; Hare and Shaw, 1965) have failed to yield adequate information on its adolescents through not having examined the patterns of morbidity over the teenage years. The comprehensive study by Warren (1965) of 187 adolescents is solely concerned with inpatients. The aim of the present study was to assess the inception rate and the services provided for adolescent psychiatric disorders, as seen at specialist clinics. Such information was particularly desirable for the City of Edinburgh, in order to provide a baseline before the establishment of an adolescent psychiatric unit in the city.

\section{Method}

Data were collected on all persons meeting the following criteria: (1) according to the method of Backett et al. (1953), they had had a disturbance in mental health resulting in at least one consultation with a psychiatrist ; (2) they were aged 14 to 19 years inclusive at the time of the first consultation (this age group was chosen because it was inclusive of all those for whom the adolescent psychiatric unit would cater) ; (3) they were resident in the City of Edinburgh on the night before consultation ; (4) they were examined by a psychiatrist during the year 1 July 1964 to 30 June 1965, having had no consultations in the previous five years; and (5) they had a measured or estimated I.Q. of 70 or over.

We did not personally examine any patients. Permission to study the case histories was obtained from all physician-superintendents and consultant psychiatrists within the area. Data were thus obtained from all hospitals and clinics which provide a psychiatric service to the citizens of Edinburgh. This procedure allowed the completion of a form which sought standard demographic data, together with the source of referral, the diagnosis (if made), and the type and duration of treatment. Where no formal diagnosis had been recorded, one of us (A.S.H.) interpreted the history and opinion to arrive at an arbitrary diagnosis. This took place in $14 \%$ of all cases.

\section{Findings}

There were 230 teenagers (106 boys and 124 girls) examined by a psychiatrist in the 12 -month period under survey. This represents an annual rate of referral to specialist services of 5.6 per thousand at risk. Fifty-four $(51 \%)$ of the boys and $60(48 \%)$ of the girls received inpatient treatment during the 12 months. Thirty-two (30\%) of the boys and $46(37 \%)$ of the girls poisoned or injured themselves before being examined by a psychiatrist. Forty-five $(42 \%)$ boys and $69(56 \%)$ girls were seen only once; of these, 19 boys and 36 girls had had a consultation after an act of self-poisoning or self-injury but were considered to have resolved their crisis and were seen not

\footnotetext{
* Members of the Scientific Staff, Medical Research Council Unit for Research on the Epidemiology of Psychiatric Illness, Edinburgh University Department of Psychiatry, Royal Edinburgh Hospital, Edinburgh 10.

+ Present address: School of Applied Social Studies, University of
}

to require further psychiatric treatrent. Eight of the boys and 19 of the girls had been given a " nil psychiatric" diagnosis but have been included in our figures because they received a psychiatric examination. No case of psychosis was found in the attempted-suicide group. Sixty-one (58\%) boys and 56 $(45 \%)$ girls were referred to the psychiatrist by their general practitioner. Only $12(11 \%)$ boys and $15(12 \%)$ girls were referred by themselves or by relatives. The court referred only four boys and three girls whom it considered to be in need of a psychiatric examination.

The diagnostic composition of the series is shown in Table I and the incidence by age, expressed as a percentage of the total, in Table II. There is no significant difference between the sexes as regards cumulative incidence by age, KolmogorovSmirnov's D statistic (Siegel, 1956) not being significant.

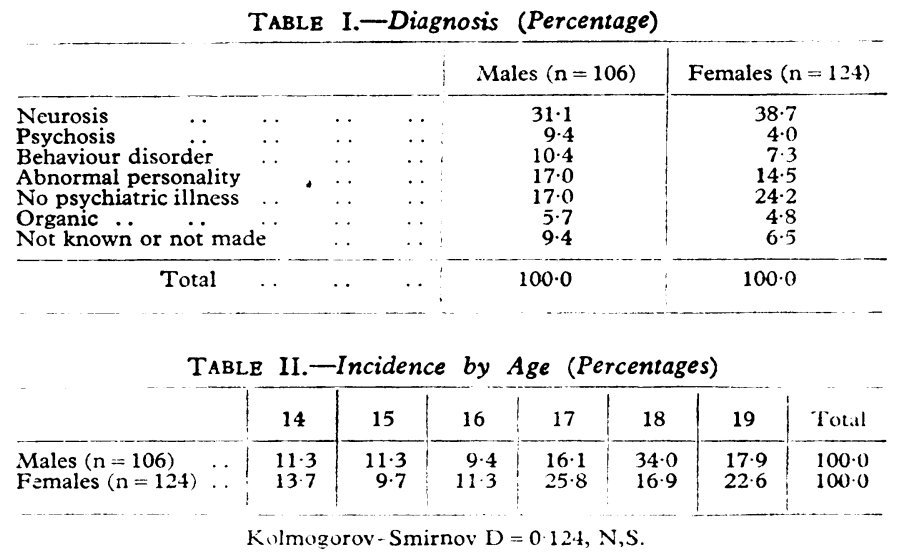

\section{Discussion}

One-half of the teenagers in this survey had had inpatient treatment largely because all cases of self-poisoning or selfinjury were seen in an inpatient setting in a medical ward of a general hospital. Approximately one-third of those adolescents reaching consultation with a psychiatrist poisoned or injured themselves first.

Contrary to the findings of Toolan (1962) in New York City, we found psychosis to be entirely absent from the 78 young people who were admitted because of self-poisoning or selfinjury.

Only half of our sample were referred by their general practitioner. This is perhaps explained by the reluctance of disturbed teenagers to seek help from a doctor who is at the same time an adult. Adolescents, by the very nature of their problems, are loath to come to adults with their emotional difficulties. It was noticeable that those who were referred by their general practitioner came from the more affluent parts of the city, while those who poisoned or injured themselves came from areas which were older, less wealthy, or less desirable for other social reasons. These social variables have been described in more detail by Philip and McCulloch (1966). The essential impulsiveness of suicidal behaviour (Kessel, 1960) may also account for the high numbers coming to psychiatric notice in 
this way. The ability of parents and friends to perceive distress in adolescents appears to vary with social class.

At a time when there has been much revised legislation dealing with the management of young offenders it is surprising that only six teenagers were referred by the court for psychiatric assessment. The setting up of family courts as recommended In the Kilbrandon Report (1964) and the establishment in Edinburgh of a unit specifically for adolescent psychiatric illness should improve the situation.

\section{Summary}

A survey is reported of referrals of adolescents to psychiatrists in Edinburgh. The annual referral rate was 5.6 per thousand at risk. For one-third of the series the consultation took place after an act of deliberate self-poisoning or self-injury ; almost one-half were referred by their family doctor and one-tenth were self-referrals. The social and emotional difficulties arising from the natural hesitance of adolescents to discuss their problems with adults are discussed.
We are grateful to Professor G. M. Carstairs for his help and advice ; to Drs. Norman Kreitman and John Evans for their criticism and advice; and to the physician-superintendents and consultant psychiatrists in the region.

\section{REFERENCES}

Backett, E. M., Shaw, L. A., and Evans, J. C. G. (1953). Proc. roy. Soc. Med., 46, 707.

Hare, E. H., and Shaw, G. K. (1965). Mental Health on a New Housing Etate. London.

Kessel, W. I. N. (1960). Brit. F. prev. soc. Med., 14, 16

Kilbrandon Committee (1964). Children and Young Persons, Scotland. Scottish Home and Health Department, Scottish Education Department. H.M.S.O., London.

Philip, A. E., and McCulloch, J. W. (1966). Brit. F. prev. soc. Med., 20, 122.

Siegel, S. (1956). Nonparametric Statistics for the Behavioural Sciences. New York.

Srole, L., Langner, T. S., Michael, S. T., Opler, M. K., and Rennie, T. A. C. (1962). Mental Health in the Metropolis: The Mid-town Manhattan Study, vol. 1. New York.

Taylor, Lord, and Chave, S. (1964). Mental Health and Environment. London.

Toolan, J. M. (1962). Amer. 7. Psychia:., 118, 71.9.

Toolan, J. M. (1962). Amer.
Warren, W. (1965). F. Child Psychol., 6, 1.

\title{
Standardization of the One-stage Prothrombin Time for the Control of Anticoagulant Therapy
}

\author{
ROSEMARY BIGGS,* M.D. ; K. W. E. DENSON,* D.PHIL.
}

Brit. med. 9., 1967, 1, 84-88

The one-stage prothrombin time test is widely used for the control of anticoagulant therapy and has proved on the whole satisfactory for this purpose. One difficulty is that the results are expressed in many different ways, and even if this is done apparently in the same way the results of one centre are seldom directly comparable to those of another. Thus if a patient moves from one centre to another there may be a change in the degree of anticoagulation. Another difficulty is that clinical trials carried out at more than one hospital may be difficult unless special steps are taken to standardize the method.

In recent years efforts have been made to solve this problem, and co-ordination should greatly improve the situation. In the United States the College of American Pathologists has reviewed the techniques in use and made some recommendations about acceptable techniques (Miale and Lafond, 1963). The Committee for Haemostasis and Thrombosis is devising a method of comparing results based on a standard thromboplastin (Biggs, 1965 ; Biggs and Denson, 1966). In England Poller (1964) has been studying the preparation of a reagent to be used in a wide area, so that all the hospitals shall have a unified method. These studies have been made from rather different points of view and are complementary to each other rather than competing, and consequently a much more constructive approach should be possible.

\section{Coagulation Defect caused by Coumarin Drugs}

The coumarin drugs cause variable reduction in the blood concentrations of clotting factors VII, IX, X, and prothrombin (II). The one-stage prothrombin time records abnormality in factors II, VII, and X, and thus in most patients gives a fair

- Medical Research Council, Blood Coagulation Research Unit, Churchill Hospital, Oxford. record of the abnormality. Since the defect is composite and it is impracticable to measure all of the factors separately, an overall assessment of the abnormality is made from the results of the test.

\section{Possibility of Standardization}

The details of technique will not be discussed, but in all of the methods the abnormality is recorded as a lengthening of clotting-time of the patient's plasma in comparison with normal. Table I gives examples of results obtained with different methods. One difficulty in comparing one method with another is clearly the different clotting-times of normal plasma -the results in Table I show a range from 13.2 to 45 seconds. This difficulty is avoided if the clotting-time ratios are calculated (Table I), because all of the normal clotting-times are expressed as a clotting-time ratio of 1 . It will be seen from Table I that if the ratios are taken as an expression of the degree of abnormality, then the methods vary a good deal in this

TABLE I.-One-stage Prothrombin Time was Carried Out on a Normal Plasma Sample and on Three Samples from Patients Receiving Anticoagulant Therapy. Six Different One-stage Techniques wero Used. The Clotting-times Obtained are Expressed in Seconds; the Clotting-time ratio is calculated by Dividing the Clotting-time for the Abnormal Sample by that of the Normal (e.g., $\frac{56}{45}=1.25$ )

\begin{tabular}{|c|c|c|c|c|c|c|c|c|c|c|c|c|}
\hline \multirow{2}{*}{ Sample } & \multicolumn{2}{|c|}{ Method 1} & \multicolumn{2}{|c|}{ Method 2} & \multicolumn{2}{|c|}{ Method 3} & \multicolumn{2}{|c|}{ Method 4} & \multicolumn{2}{|c|}{ Method 5} & \multicolumn{2}{|c|}{ Method 6} \\
\hline & C. & R. & C. & $\mathrm{R}$. & C. & R. & C. & R. & c. & R. & C. & R. \\
\hline Normal & 45 & $1 \cdot 0$ & 44 & $1 \cdot 0$ & $13 \cdot 2$ & $1 \cdot 0$ & 19 & $1 \cdot 0$ & $19 \cdot 7$ & $1 \cdot 0$ & 14 & $1 \cdot 0$ \\
\hline $\begin{array}{l}1 \\
\text { Patient }\end{array}$ & 56 & $1 \cdot 25$ & 50 & $1 \cdot 13$ & 14 & 1.08 & 21 & $1 \cdot 1$ & $22 \cdot 5$ & $1 \cdot 24$ & $15 \cdot 7$ & $1 \cdot 12$ \\
\hline $\begin{array}{c}2 . . \\
\text { Patient }\end{array}$ & 120 & $2 \cdot 65$ & 96 & $2 \cdot 2$ & 19 & $1 \cdot 44$ & 35 & $1 \cdot 85$ & 38 & 1.94 & 21.5 & 1.54 \\
\hline $3 \ldots$ & 106 & $2 \cdot 35$ & 82 & 1.87 & $18 \cdot 8$ & $1 \cdot 42$ & 38 & $2 \cdot 0$ & 33 & 1.68 & 21 & 1.72 \\
\hline
\end{tabular}

